Article

\title{
Investigating Seasonal Effects of Dominant Driving Factors on Urban Land Surface Temperature in a Snow-Climate City in China
}

\author{
Chaobin Yang ${ }^{1, *(\mathbb{D}}$, Fengqin Yan ${ }^{2}$, Xuelei Lei ${ }^{1}$, Xiuli Ding ${ }^{1}$, Yue Zheng ${ }^{1}$, Lifeng Liu ${ }^{1}$ and \\ Shuwen Zhang ${ }^{3}$ \\ 1 School of Civil and Architectural Engineering, Shandong University of Technology, Zibo 255000, China; \\ 16120906090@stumail.sdut.edu.cn (X.L.); 16120906087@stumail.sdut.edu.cn (X.D.); \\ 16120906086@stumail.sdut.edu.cn (Y.Z.); tangshanllf@sdut.edu.cn (L.L.) \\ 2 State Key Laboratory of Resources and Environmental Information System, Institute of Geographic Sciences \\ and Natural Resources Research, Chinese Academy of Sciences, Beijing 100101, China; yanfq@lreis.ac.cn \\ 3 Northeast Institute of Geography and Agroecology, Chinese Academy of Sciences, Changchun 130102, \\ China; zhangshuwen@iga.ac.cn \\ * Correspondence: yangchaobin@sdut.edu.cn
}

Received: 2 August 2020; Accepted: 14 September 2020; Published: 15 September 2020

\begin{abstract}
Land surface temperature (LST) is a crucial parameter in surface urban heat island (SUHI) studies. A better understanding of the driving mechanisms, influencing variations in LST dynamics, is required for the sustainable development of a city. This study used Changchun, a city in northeast China, as an example, to investigate the seasonal effects of different dominant driving factors on the spatial patterns of LST. Twelve Landsat 8 images were used to retrieve monthly LST, to characterize the urban thermal environment, and spectral mixture analysis was employed to estimate the effect of the driving factors, and correlation and linear regression analyses were used to explore their relationships. Results indicate that, (1) the spatial pattern of LST has dramatic monthly and seasonal changes. August has the highest mean LST of $38.11^{\circ} \mathrm{C}$, whereas December has the lowest $\left(-19.12{ }^{\circ} \mathrm{C}\right)$. The ranking of SUHI intensity is as follows: summer $\left(4.89^{\circ} \mathrm{C}\right)>$ winter with snow cover $\left(1.94^{\circ} \mathrm{C}\right)$ $>$ spring $\left(1.16^{\circ} \mathrm{C}\right)>$ autumn $\left(0.89^{\circ} \mathrm{C}\right)>$ winter without snow cover $\left(-1.24{ }^{\circ} \mathrm{C}\right)$. (2) The effects of driving factors also have seasonal variations. The proportion of impervious surface area (ISA) in summer $(49.01 \%)$ is slightly lower than those in spring (56.64\%) and autumn (50.85\%). Almost half of the area is covered with snow $(43.48 \%$ ) in winter. (3) The dominant factors are quite different for different seasons. LST possesses a positive relationship with ISA for all seasons and has the highest Pearson coefficient for summer $(r=0.89)$. For winter, the effect of vegetation on LST is not obvious, and snow becomes the dominant driving factor. Despite its small area proportion, water has the strongest cooling effect from spring to autumn, and has a warming effect in winter. (4) Human activities, such as agricultural burning, harvest, and different choices of crop species, could also affect the spatial patterns of LST.
\end{abstract}

Keywords: land surface temperature; driving factors; seasonal comparison; snow climate; Changchun city

\section{Introduction}

Urbanization has occurred at an unprecedented rate and is considered as one of the most important drivers of dramatic changes in land use and land cover (LULC) [1,2]. Transformation from natural surfaces to various man-made impervious surfaces (e.g., parking lots, roads, and buildings) made of concrete, asphalt, and metal has resulted in the alteration of land surface characteristics, including land 
surface temperature (LST), hydrothermal condition, landscape composition, and albedo, which have led to the phenomenon known as urban heat island (UHI), wherein urban areas tend to have warmer climates than their surrounding areas [3-5]. UHI has been proved to significantly affect air and water quality, energy consumption, regional climate, and human health [6-8]. Therefore, given the severity of the negative effects of UHI, there is a need for a better understanding and monitoring of the driving factors, contributing to the occurrence of UHI, to improve the quality of urban environments and to develop sustainable urban development policies.

Air temperature and LST are the two most used indicators in UHI studies [9,10]. Traditionally, UHI characterized by air temperature, collected from fixed weather stations or mobile vehicles, is known as canopy UHI (CUHI) [11]. Air temperature has advantages in terms of high temporal resolution and high accuracy, and thus can be employed in conducting CUHI studies at a fine time scale [12-14]. Nevertheless, the limited stations fail to provide detailed spatial information regarding CUHI. Previous studies have shown that the relationships between LST and air temperature are statistically significant, and UHI, quantified using retrieved LST from thermal remote sensing, has been defined as the surface UHI (SUHI) [15-17]. LST is one of the primary indicators for examining SUHI because it is related to surface radiation and energy exchange, and helps us to explicitly reveal sufficient spatial patterns of the urban thermal environment, despite being subject to the time of satellite overpass [18,19]. However, LST estimated from remote sensing is easily influenced by urban surface properties and background climates. As a result, the spatiotemporal variations (from global to city level, and from interannual, seasonal, and monthly, to diurnal, nocturnal, and even hourly level) of the urban thermal environment spatial pattern has been explored by many studies [19-24].

To investigate the formation and driving mechanism of SUHI, numerous studies examined the relationships between LST and its driving factors [20,25-32]. The driving factors could be roughly classified into three categories: surface biophysical parameters, landscape component and configuration factors, and socioeconomic factors [27]. The surface biophysical parameters were usually composed of many spectral indices, among which normalized difference vegetation index (NDVI), normalized difference building index (NDBI), and normalized difference water index (NDWI) were the most used because they are easily calculated $[26,33]$. However, although they exhibited good linear relationships with LST, the relationship between LST and NDVI suffers from evident seasonal changes [11]. Therefore, these factors were still insufficient for fully exploring the characteristics of an urban thermal environment. For landscape components, land-cover types obtained based on a per-pixel classification method and the abundance of different driving factors estimated via spectral mixture analysis (SMA), and based on sub-pixel classification, were often employed in studies exploring their effects on LST [34]. However, because of the problem with mixing pixels in Landsat images (30 $\mathrm{m}$ spatial resolution) of urban areas, per-pixel classification, compared to sub-pixel classification, may lead to under- or over-estimation for certain land-cover types. Furthermore, despite high-spatial-resolution images (e.g., Quickbird, WorldView, GF-2) being able to provide detailed information on land cover, they are also more expensive. On the other hand, when free-access Landsat series images are used to obtain information on landscape components, it is essential to perform a comprehensive examination of the fraction of each feature within a pixel. Ridd proposed a "vegetation-impervious surface-soil" (V-I-S) model, wherein he assumed that the urban area pixels were combinations of vegetation, impervious surface area (ISA), and soil [35]. It is widely acknowledged that ISA is one of the most important driving factor accounting for most of the variations in LST dynamics, and area proportion of vegetation estimated via SMA was determined in SUHI studies to be a better indicator for characterizing information on vegetation $[11,34,36,37]$. Thus, driving factors influencing urban surface biophysical composition were found to be the best indicators for studying seasonal variations of LST across space [38]. Human activities, such as changes in population density, gross domestic product (GDP), and nighttime light were proved to also affect the LST $[39,40]$. However, they were rarely used in SUHI studies because of the difficulty in accessing accurate data [27]. Among the analytical methods used to 
investigate the effect of driving factors on LST, the Pearson correlation analysis and the linear regression model were the dominant choices and proved to be effective for the given purpose [2,4,41,42].

Even though the effects of driving factors on LST have been widely explored, some deficiencies still exist in the current literature. First, relevant SUHI research has been focused on tropical, subtropical, and temperate cities, whereas a snow-climate city like Changchun should be given more attention, although several studies have been conducted in the city [26,43-47]. In Cici Alexander's paper, AlgAarhus Kommune in Denmark was selected as the study area, as relevant research is under-represented and sensitive at high latitudes [26]. The city has high latitudes, above $55^{\circ}$, and has an average annual temperature of $7.8^{\circ} \mathrm{C}$, which is even higher than that of Changchun $\left(5.5^{\circ} \mathrm{C}\right)$. This motivated us to choose Changchun in China to conduct our research. Snow-climate cities have quite different climate features compared to those of low and other mid-latitude cities. Second, because of seasonal changes in received incoming solar radiation and solar altitude, it is worth investigating the seasonal combined effect of driving factors on LST, rather than assessing the effect of one factor in a single season. Third, although LST is influenced by many driving factors, the dominant influencing factor needs to be determined and further explored. Fourth, Changchun has four seasons with a very long and cold winter. Its special climate characteristics make Changchun an appropriate place for investigating the seasonal effects of driving factors on the spatial pattern of an urban thermal environment. We hope our study can enrich SUHI case studies in snow-climate areas with long and cold winters.

This study used Changchun, China, for its case study, investigated the seasonal effect of driving factors on urban LST, and conducted a seasonal comparison study. Twelve Landsat 8 images were used to retrieve LST for different months, and five driving factors (ISA, vegetation, soil, snow, and water) were calculated via SMA for different seasons. This study has three main objectives: (1) to map the spatial patterns of LST and driving factors simultaneously for different seasons; (2) to quantify the relationships between LST and each of the five driving factors, to identify which factor is the dominant one; and (3) to explore how these relationships have changed over different seasons. The goal of this study is to improve our understanding of the formation and driving mechanism of SUHI in snow-climate cities, and thus help in developing sustainable development policies for these cities.

\section{Materials and Methods}

\subsection{Study Area}

Changchun city $\left(125^{\circ} 06^{\prime}-125^{\circ} 36^{\prime} \mathrm{E}, 43^{\circ} 43^{\prime}-44^{\circ} 04^{\prime} \mathrm{N}\right.$ ) (Figure 1), the capital of Jilin province, is located in the northeast part of China, with nearly 4.45 million urban residents in 2019, based on the local Bureau of Statistics. The city is flat and located about $250-350 \mathrm{~m}$ above sea level. The climate of Changchun is classified by the Köppen-Geiger climate classification system as Dwa, or a snow climate with a dry winter and hot summer, and with an average precipitation of $561.6 \mathrm{~mm}$ [48]. July is the warmest month, with an average daily air temperature of $23.1^{\circ} \mathrm{C}$, whereas January is the coldest $\left(-15.6^{\circ} \mathrm{C}\right)$ [47]. As a result, Changchun, which covers the 5th ring road, with an area of $523.3 \mathrm{~km}^{2}$, was selected as our study area. 


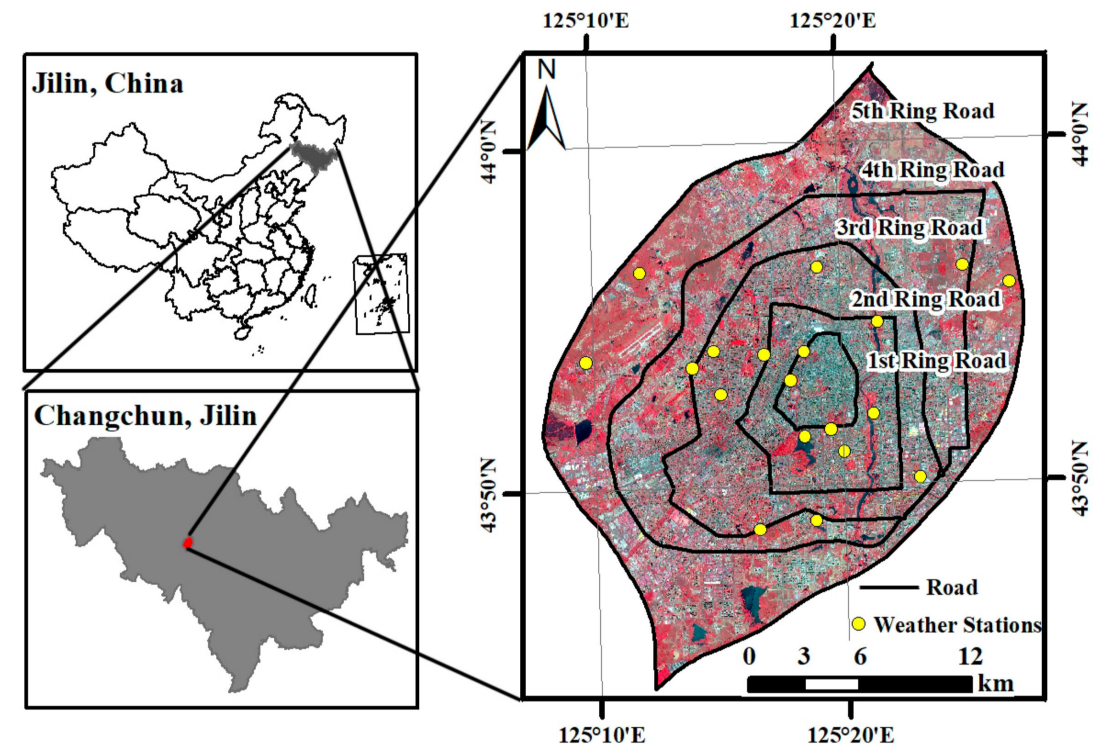

Figure 1. Location of Changchun City (false-color image).

\subsection{Datasets}

Twelve cloud-free Landsat 8 OLI (operational land imager) and TIRS (thermal infrared sensor) images (Path/Row:118/30), with a resampled spatial resolution of $30 \mathrm{~m}$ for all bands, were collected from the Geospatial Data Cloud of China (http://www.gscloud.cn/) and the United States Geological Survey website (http://earthexplorer.usgs.gov/), to retrieve LST and driving factors for this study. The data were acquired at approximately 10:21 a.m. local time in 2014 and 2016, because of the difficulty of obtaining all the 12-month images under clear-sky conditions in a single year. As a result, we assumed that the same month in different years would have similar urban thermal environments, and that the differences in LST for different months were significant. Information on the images is listed in detail in Table 1. Radiation correction and atmospheric correction were applied to the OLI images using ENVI 5.3 FLAASH Atmospheric Correction tools, where needed parameters could be found in the image's metadata before the driving factors were calculated. Atmospheric correction was included in the LST retrieval method employed in this study, and was therefore not implemented with the TIRS images. Finally, a vector layer of the 5th ring road of Changchun was used to clip each dataset.

Table 1. Acquisition dates of Landsat 8 images and Google Earth images used in this study.

\begin{tabular}{|c|c|c|c|c|c|c|c|c|c|c|c|c|}
\hline \multirow{2}{*}{$\begin{array}{l}\text { Season } \\
\text { Month }\end{array}$} & \multicolumn{3}{|c|}{ Winter } & \multicolumn{2}{|c|}{ Spring } & \multicolumn{3}{|c|}{ Summer } & \multicolumn{2}{|c|}{ Autumn } & \multicolumn{2}{|c|}{ Winter } \\
\hline & Jan. & Feb. & Mar. & Apr. & May. & Jun. & Jul. & Aug. & Sep. & Oct. & Nov. & Dec. \\
\hline Landsat 8 & $\begin{array}{c}\text { 4 January } \\
2014\end{array}$ & $\begin{array}{l}21 \text { February } \\
2014\end{array}$ & $\begin{array}{l}\text { 3 March } \\
2016\end{array}$ & $\begin{array}{c}\text { 10 April } \\
2014\end{array}$ & $\begin{array}{l}\text { 17 May } \\
2016\end{array}$ & $\begin{array}{l}\text { 13 June } \\
2014\end{array}$ & $\begin{array}{c}\text { July } 4 \\
2016\end{array}$ & $\begin{array}{c}5 \text { August } \\
2016\end{array}$ & $\begin{array}{c}17 \text { September } \\
2014\end{array}$ & $\begin{array}{c}3 \text { October } \\
2014\end{array}$ & $\begin{array}{c}4 \text { November } \\
2014\end{array}$ & $\begin{array}{l}\text { 27 December } \\
2016\end{array}$ \\
\hline
\end{tabular}

Air temperature (AT) was obtained from 19 weather stations located in the study area, which are operated by the Meteorological Bureau of Changchun city. As access was limited to year-round data, AT was collected only at 10:00 a.m. and 11:00 a.m. local time, on August 5 (for summer) and December 27 (for winter) in 2016, when the Landsat 8 images were acquired synchronously. On one hand, AT was employed to validate the accuracy of the retrieved LST. On the other hand, we could perform a comparison study to explore the difference between LST and AT in characterizing the urban thermal environment. High-spatial-resolution Google Earth images, acquired on the same season and similar months, were also used to help identify the different statuses (such as growth situation of vegetation) of driving factors in different places and different seasons, given that the Landsat 8 images had a coarse resolution (Table 1). It was hard to obtain Google Earth images which had the identical 
acquisition dates as Landsat 8 . In this study, it made sense to compare Landsat 8 and Google Earth if they had the same acquisition month, as we assumed that the status of driving factors in the same month would have similar features, although obtained in adjacent years. As listed in Table 1, all the Landsat 8 images, and most of the Google Earth images, were acquired from 2014 to 2016 in this study, and the effect of LULC changes on the status of the driving factors could be neglected. No Google image was available in December 2016 for the study area, and was therefore replaced with another image from December 2013.

\subsection{Methods}

\subsubsection{Retrieval of LST}

Band 10 of the Landsat 8 TIRS images was used to estimate the monthly LST of Changchun city. Band 11 was not recommended for retrieving LST because of technical problems [49]. The original digital number of each pixel in band 10 was first converted to the top-of-atmosphere brightness temperature (BT), which is the effective temperature viewed via satellite, under an assumption of unity emissivity, using the radiometric calibration tool in ENVI 5.3 software (Harris Geospatial Solutions, Broomfield, CO, USA). The BT was then corrected for the varied emissivities of the different land-cover types. Finally, the LST $\left({ }^{\circ} \mathrm{C}\right)$ could be calculated using the following:

$$
T_{s}=\frac{T_{b}}{1+\left(\lambda T_{b} / \rho\right) \ln \varepsilon}-273.15
$$

where $T_{s}$ is the LST, and $T_{b}$ refers to BT; $\lambda$ is a wavelength of $10.9 \mu \mathrm{m}$ for TIRS band 10; and $\rho=1.43 \times 10^{-2} \mathrm{mK} . \varepsilon$ is the land surface emissivity (LSE), a very important factor for accurate LST retrieval. The NDVI threshold method was adopted in this study to estimate LSE [50]. The NDVI was calculated as follows:

$$
N D V I=\frac{N I R-R}{N I R+R}
$$

where NIR and $R$ are band 5 and band 4, respectively, for Landsat 8 OLI. If NDVI was greater than 0.5, then the pixel was considered as fully vegetated, the LSE of which was assigned a value of 0.99 . If the NDVI was smaller than 0.2 , the emissivity of the pixel was estimated to be 0.97 . The LSE of surfaces for $0.2<\mathrm{NDVI}<0.5$ was calculated as follows:

$$
\varepsilon=0.986+0.004 \times F_{v}
$$

where $F_{v}$ is the vegetation fraction, estimated from NDVI, and is calculated as follows:

$$
F_{v}=\frac{N D V I-N D V I_{s}}{N D V I_{v}-N D V I_{s}}
$$

where $N D V I_{v}$ is the NDVI value of pure vegetation and has a value of 0.5 , and $N D V I_{S}$ is bare soil or non-vegetation, and is assigned a value of 0.2 . More details about LST estimation can be found in a previous study [50].

\subsubsection{Indicator of SUHI Intensity}

The SUHI intensity is defined as the LST difference between urban and rural areas. In this study, the SUHI intensity was calculated as follows:

$$
\text { SUHI intensity }=L S T_{1 \text { th Ring }}-L S T_{4-5 \text { Ring }}
$$

where $L S T_{1 \text { th Ring }}$ represents the urban thermal environment and is defined as the average LST of the 1st ring road, and $L_{S T} T_{4-5 \text { Ring }}$ is the average LST of the area between the 4 th and 5 th ring roads, which was considered as a rural area. The SUHI intensity was computed for all 12 months. 


\subsubsection{Retrieval of Driving Factors}

Land surface characteristics could affect the spatial pattern of LST to a large extent. In our study, five indicators were selected as the driving factors: water, vegetation, ISA, soil, and snow. The reasons why these five elements were chosen were: (1) a snow-climate city usually consists of these five factors, by which the urban area could be well depicted, and (2) these factors are less sensitive to changes in atmospheric condition, (3) are easily calculatable, and (4) have been widely used as influencing factors in LST studies, but need to be re-examined for their relationships with LST, for different seasons.

The modified normalized difference water index (MNDWI) proposed by $\mathrm{Xu}$ was employed in extracting water body features for this study [51] and was calculated as follows:

$$
M N D W I=\frac{\text { Green }-M I R}{\text { Green }+M I R}
$$

where Green and MIR are band 3 and band 6, respectively, for Landsat 8 OLI. Based on visual interpretation, if the MNDWI values of the pixels were higher than 0.3 , they were treated as pure water bodies.

The idea of a "V-I-S" model, raised by Ridd, was used to estimate the abundance of each driving factor [35]. Based on the theory of spectral unmixing, a constrained linear spectral mixture analysis (LSMA) was applied [52,53], and it assumed that the reflectance of each pixel was a linear combination of reflectance of different endmembers (different land-cover types):

$$
R_{b}=\sum_{i=1}^{N} f_{i} R_{(i, b)}+e_{b}
$$

subject to

$$
\sum_{i=1}^{N} f_{i}=1 \text { and } 0 \leq f_{i} \leq 1,
$$

where $R_{b}$ is the reflectance of band $b, f_{i}$ is the abundance of endmember $\left(f_{i}\right), R_{(i, b)}$ is the reflectance of endmember $\left(f_{i}\right)$, and $e_{b}$ is the residual. First, five pure endmembers, i.e., vegetation, soil (excluding for winter), snow (only for winter), high albedo, and low albedo, were selected manually on the fused Landsat 8 OLI images to obtain their responding curves, on spectrum-based high-resolution Google Earth images. The snow endmember was selected to replace soil in winter because the study area was usually covered with snow during most of the season. LSMA was then performed to obtain the abundance of each endmember. The abundance of ISA could be calculated as the sum of low albedo and high albedo. Finally, the water bodies were removed from all the abundance images via the application of an MNDWI mask. For the results, if the ISA value of a pixel is 0.85 , it signifies that $85 \%$ of the pixel was covered with impervious areas (buildings, roads, or parking lots). An accuracy assessment conducted using 150 samples with $5 \times 5$ pixels revealed that more than $80 \%$ of the absolute errors of the samples were less than 0.1 .

\subsubsection{Statistical Analysis and Sample Selection}

To investigate the relationships between the driving factors and LST, the study area was divided into 577 grids at a scale of $1 \times 1 \mathrm{~km}^{2}$ (Figure 2), and each grid was treated as a statistical sample. First, Pearson correlation analysis was performed to explore their correlations. The ordinary least-squares linear regression model was then applied to explore the influence of each factor on LST. For each season, the average LST of each grid was regarded as the dependent variable, and the abundances of the five factors were treated as independent variables. The LST was not affected by only one single factor. However, the problem of multicollinearity prevented our endeavor to conduct multivariate linear regression model analysis, to quantify the relative contributions of the different driving factors to LST. Fortunately, in this study, the Origin software made it possible to qualitatively analyze the relationship between LST and the different components of each grid by generating a figure that showed information on the area, proportions of different factors, and LST synchronously. 


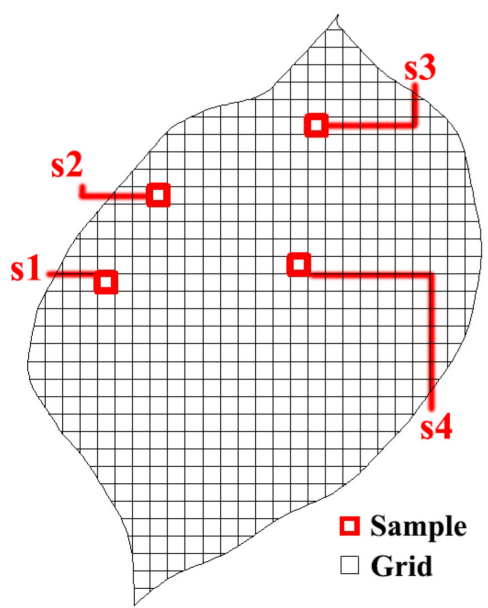

Figure 2. Grid $\left(1 \times 1 \mathrm{~km}^{2}, 577\right.$ in total) map and four samples (s1-s4) of the study area.

Based on the principle that both the spatial pattern of LST and the status of a driving factor were changed distinctly, four samples (s1-s4) (Figure 2) were selected to explore the seasonal changes of the effects of phenology and potential human activities on variations in the LST, in a spatially explicit way. Each sample had 12 corresponding figures, including 4 LST maps, 4 Landsat 8 false-color maps, and 4 spatially corresponding Google Earth maps for spring, summer, autumn, and winter. As a result, there were 48 figures in total.

\section{Result}

\subsection{Monthly Spatial Pattern of LST}

To assess the accuracy of LST retrieval, Pearson correlation analysis was performed using the air temperature and corresponding mean LST for $5 \times 5$ pixels near each weather station. The results show that the coefficients between them were 0.52 in summer and 0.76 in winter, and that they were all statistically significant at a level of 0.05 . The results of the linear regression model indicate that there was a good consistency between LST and observed air temperature (Figure 3).
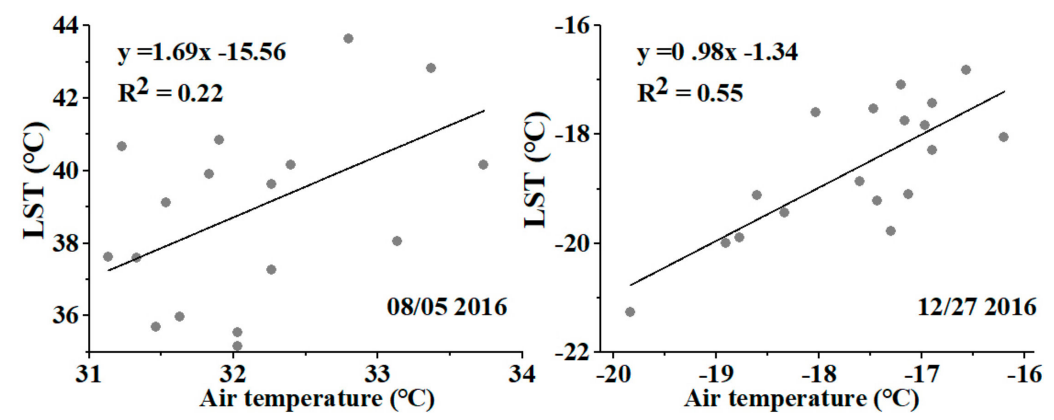

Figure 3. Correlations between land surface temperature (LST) and air temperature.

The spatial distribution of LST for different months is shown in Figure 4. It can be clearly seen that the thermal environment of Changchun had remarkable monthly variations. The high-LST areas were concentrated mainly inside the 3rd ring road for most months (June, July, August, December, and January); these areas were assembled with dense buildings. Commercial lands with little vegetation were usually located in the central city and generated higher LST because of the transformation of the natural environment to artificial surfaces, such as asphalt and concrete. However, for April, September, and October, the high-LST regions were distributed sporadically, and it was difficult the find a typical SUHI phenomenon because there were some hot spots in the rural area. For February, 
March, and November, especially, the values of LST inside the 2nd ring road were much lower than those in the surrounding areas, and thus an "inverse SUHI" was observed. During these months, very-high-LST regions could be found in the west, northwest, and northeast parts of the study area, where croplands were the dominant land-cover type. This very interesting phenomenon attracted our attention, and we will explore the driving force in the following discussion.

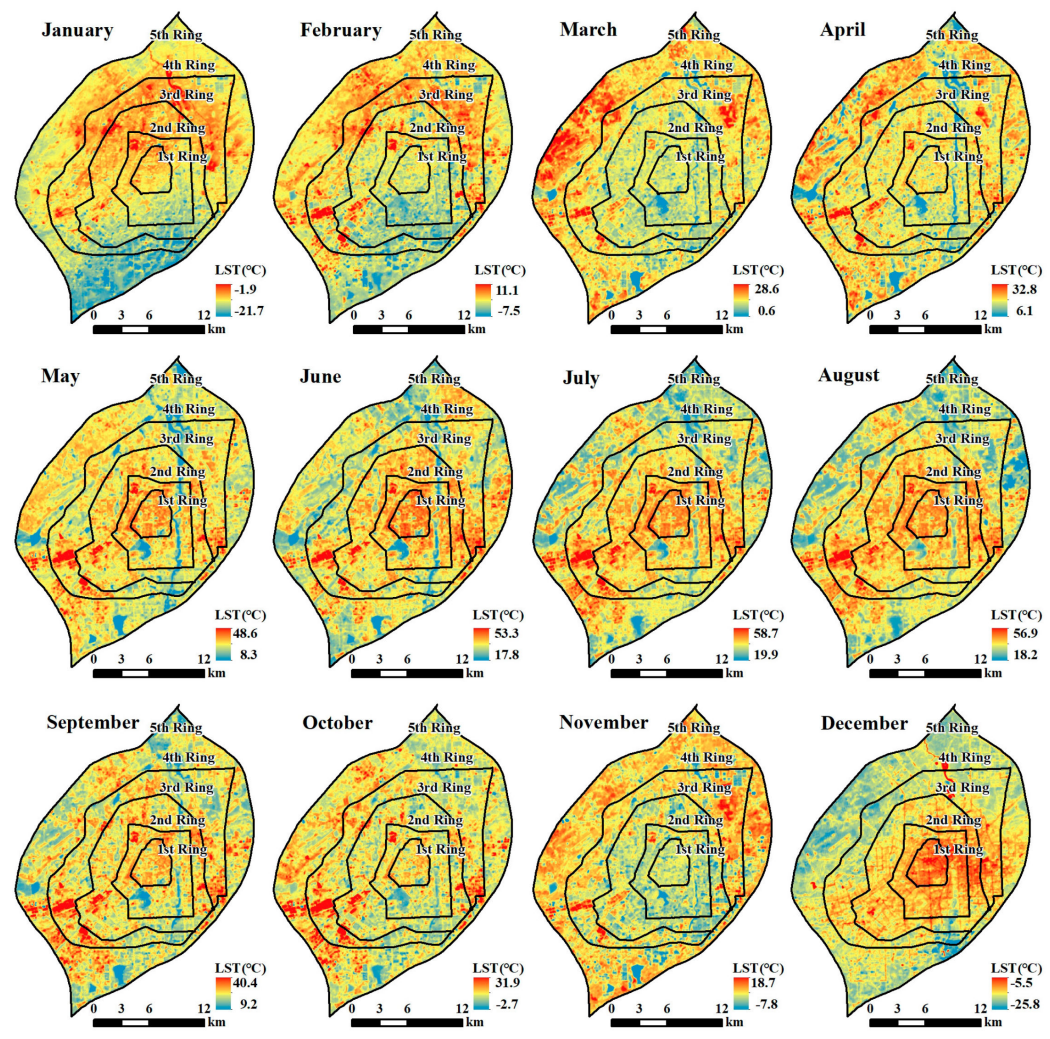

Figure 4. Spatial distributions of LST for different months.

In addition to the monthly variations, several similar spatial patterns of LST were also observed. For example, from April to September, the Yitong River, which is the mother river of Changchun city, flowing from south to north, always had a lower LST, and formed a "strip" of cooling area. However, in December and January, the LST of the north part was much higher than in other areas, which may have been because the north part of the river was not frozen. On the other hand, the China FAW Group Corporation was in the southwest part of Changchun, which had a higher LST from January to December because of dense ISA and industrial activities.

\subsection{Monthly Variation of SUHI Intensity}

The average LST of the 1st to 5th ring roads is visualized in Figure 5. The mean LST of the 5th ring road is notably also the average LST of the whole study area. December had the lowest LST $\left(-19.12{ }^{\circ} \mathrm{C}\right)$, followed by January $\left(-12.97^{\circ} \mathrm{C}\right)$, and February $\left(-0.53{ }^{\circ} \mathrm{C}\right)$. The LST values of the other nine months were all higher than zero, and August had the highest average LST, at $38.11^{\circ} \mathrm{C}$. The mean LSTs for May $\left(30.57^{\circ} \mathrm{C}\right)$, June $\left(34.74{ }^{\circ} \mathrm{C}\right)$, and July $\left(37.61^{\circ} \mathrm{C}\right)$ were higher than $30{ }^{\circ} \mathrm{C}$. 


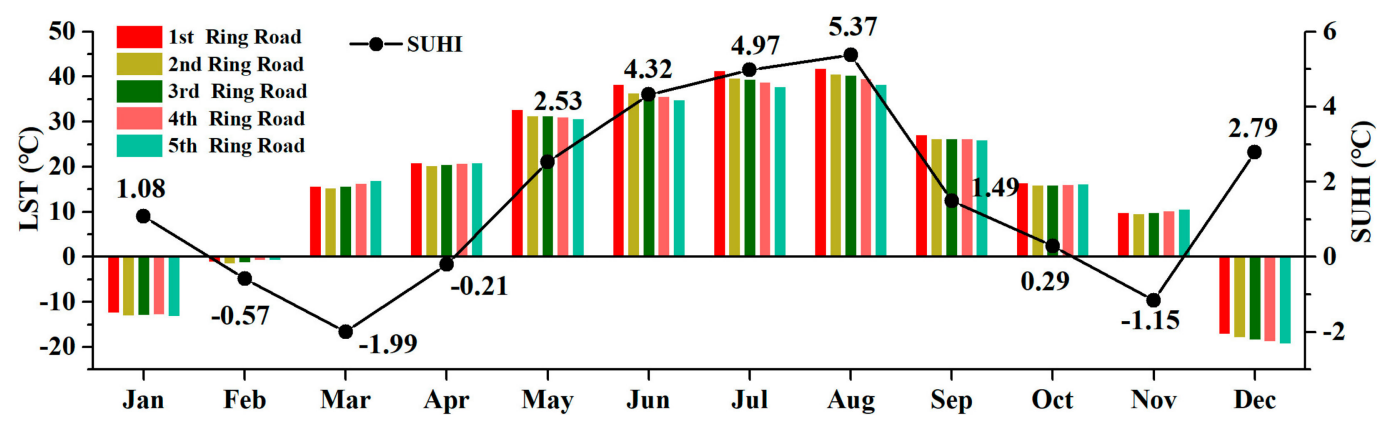

Figure 5. Monthly average LST for the five ring roads, and surface urban heat island (SUHI) intensity.

The monthly variations in SUHI intensity are also presented in Figure 5. The change trend for SUHI intensity declined from January $\left(1.08^{\circ} \mathrm{C}\right)$ to March $\left(-1.99^{\circ} \mathrm{C}\right)$, then gradually increased to August $\left(5.37^{\circ} \mathrm{C}\right)$. It declined again from August to November $\left(-1.15^{\circ} \mathrm{C}\right)$ and increased to $2.79^{\circ} \mathrm{C}$ in December. From a comparison of the average LST and SUHI of each month, it was not difficult to find that a low LST did not indicate a weak SUHI intensity. For example, December had the lowest LST, whereas the SUHI was $2.79^{\circ} \mathrm{C}$, which was much higher than for other months with higher average LST, such as April (average LST of $20.73{ }^{\circ} \mathrm{C}$ ). For February, April, and October, the absolute value of SUHI was less than $1{ }^{\circ} \mathrm{C}$, indicating that the LST difference between urban and rural areas was not significant. Corresponding to the spatial patterns of LST for March and November, the SUHI were -1.99 and $-1.15^{\circ} \mathrm{C}$, respectively, which signified that urban areas had a much lower LST than that in rural areas. For seasonal variations, from the highest to lowest, the ranking of SUHI was as follows: summer $\left(4.89^{\circ} \mathrm{C}\right)>$ winter (December and January in this study) with snow cover $\left(1.94^{\circ} \mathrm{C}\right)>$ spring $\left(1.16^{\circ} \mathrm{C}\right)>$ autumn $\left(0.89^{\circ} \mathrm{C}\right)>$ winter without snow cover $\left(-1.24^{\circ} \mathrm{C}\right)$. However, many studies in a similar cold-climate city (such as Beijing) have suggested that winter has the strongest UHI effect [54,55]. These conclusions are based on air temperature data, rather than the LST used in our study. The different data may cause different results. Another question is how to define urban and rural areas [15]. Different definitions may also generate different results. Although Beijing and Changchun are classified as cold-climate cities, their climates in winter are quite different. Changchun's winter is much longer and colder, and it is usually covered with snow in the coldest months. However, the snow in Beijing is more likely to melt. Different data, methods, and climate background may yield different results.

\subsection{Seasonal Spatial Pattern of Driving Factors}

Temperature is an environmental factor that changes all the time, and thus it is necessary to explore the monthly variations in LST, as listed in Sections 4.1 and 4.2. However, monthly changes in the driving factors are relatively slow, and therefore a seasonal contrast analysis was performed in our study. Through the use of the methods mentioned in Section 2.3, the seasonal distributions of ISA, vegetation, soil, and snow are visualized in Figure 6. Water is not included in Figure 6 because it accounted for less than $2 \%$ of the whole study area, as shown in Table 2. The seasonal distributions of LST were averaged based on the corresponding months. Therefore, a visual comparison between thermal environment and driving factors could be easily performed. The LST for winter, especially, was averaged based only on December and January, when Changchun was covered with snow, to explore the effect of snow on LST. 

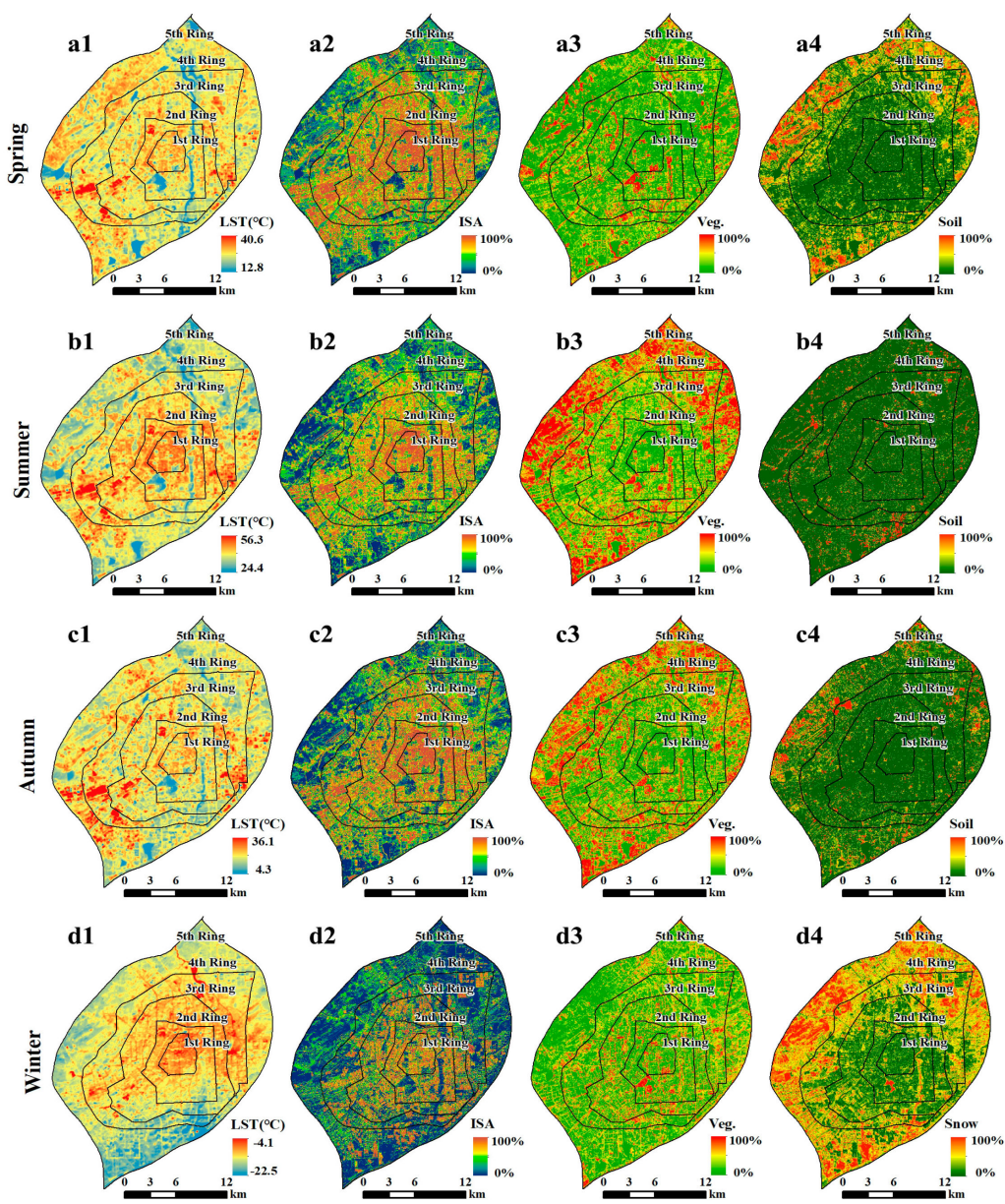

Figure 6. Seasonal distributions of LST, impervious surface area (ISA), vegetation (Veg.), soil, and snow. (for 'a1-d4': 'a-d' represent different seasons, a for Spring, b for Summer, c for Autumn and d for winter; ' $1-4$ ' represent LST and factors, 1 for LST, 2 for ISA, 3 for Veg. and 4 for soil (snow)).

Table 2. Area proportions of driving factors in different seasons.

\begin{tabular}{cccccc}
\hline Season & ISA & Vegetation & Soil (Snow) & Water & Total \\
\hline Spring & $56.64 \%$ & $19.14 \%$ & $22.58 \%$ & $1.64 \%$ & $100 \%$ \\
Summer & $49.01 \%$ & $46.23 \%$ & $3.23 \%$ & $1.53 \%$ & $100 \%$ \\
Autumn & $50.85 \%$ & $40.59 \%$ & $7.26 \%$ & $1.30 \%$ & $100 \%$ \\
Winter & $34.38 \%$ & $22.13 \%$ & $43.48 \%$ & $0.01 \%$ & $100 \%$ \\
\hline
\end{tabular}

The distributions of LST for summer (Figure 6(b1)) and winter (Figure 6(d1)) had similar spatial patterns, wherein the high-LST area was concentrated in the city center. On the other hand, the low LST was located mostly outside the 4th ring road. Meanwhile, for spring and autumn, although there were several hot spots in the southwest, it was difficult to observe obvious differences between the 1st ring road and 5th ring road. For winter, several low-LST areas were observed inside the city; however, these areas were not observed for other seasons. This pattern may be due to certain characteristics that were present only in winter.

Despite some seasonal variations in the distribution of ISA, most of the ISA were observed to be distributed inside the 4 th ring road for all seasons. However, the area proportion of ISA for winter $(34.38 \%)$ (Figure 6(d2)) was much less than that for spring (56.64\%) (Figure 6(a2)). One possible explanation was that some of the flat ISA was covered with snow in winter, and thus these areas were classified with snow factors. 
Meanwhile, different from the ISA, the distributions of vegetation and soil (snow) had considerable seasonal variations because the status of vegetation growth could change significantly among different seasons. In spring (Figure 6(a3)), the trees began to turn green earlier than the crops, and high values of vegetation abundance could be found in parks, and along Yitong River. At this time, most crops had not yet been sowed, and therefore the west, northeast, and south parts of the study area were covered with soil, as shown in Figure 6(a4). However, in summer (Figure 6(b3)), the area proportion of vegetation was $46.23 \%$, and was much higher than that in spring (19.14\%) because the crops (most of which were corn) had been growing very fast after cultivation. As a result, there was little soil (3.23\%) in summer (Figure 6(b4)). In autumn, the area proportion of vegetation declined as farmers began to harvest. If one farmland was harvested earlier, it changed from vegetation to soil again, such as in the west part in autumn (Figure 6(c4)). There were some under-construction-site areas that were also classified as soils. In winter, most of the corps had been harvested, and the lands were covered with snow (Figure 6(d4)). The snow became the dominant factor in winter, with an area proportion of approximately $43.48 \%$. There were almost no liquid water bodies in winter (less than $0.01 \%$ ).

\subsection{Relationships between LST and Driving Factors}

From a comparison of the spatial patterns of LST and driving factors in Figure 6, a general conclusion could be made: that high LST was related to ISA, and that lower LST was usually located in the vegetation and snow areas, which was consistent with previous studies [11,26]. However, the quantitative analysis of their relationships in different seasons should be explored in detail. The Pearson correlation coefficients (PCC) between LST and the indicators are listed in Table 3. LST had positive relationships with ISA for all seasons, and the coefficient was 0.89 for summer, which was much larger than for the other seasons. Negative linear relationships between LST and vegetation were found for all seasons except winter $(\mathrm{PCC}=0.05)$, and similarly, the cooling effect of vegetation was strongest in summer. From spring to autumn, the relationships between LST and soil were not significant. Although the study area had few water bodies, the LST had significant negative relationships with these bodies of water. However, a positive correlation $(\mathrm{PCC}=0.21$ ) between LST and liquid water was observed for winter.

Table 3. Pearson correlation coefficients between driving factors and LST for different seasons.

\begin{tabular}{ccccc}
\hline Season & ISA & Vegetation & Soil (Snow) & Water \\
\hline Spring & $0.37 *$ & $-0.50^{*}$ & 0.04 & $-0.65^{*}$ \\
Summer & $0.89 *$ & $-0.81^{*}$ & 0.00 & $-0.37^{*}$ \\
Autumn & $0.49^{*}$ & $-0.47^{*}$ & $-0.10^{*}$ & $-0.36^{*}$ \\
Winter & $0.43^{*}$ & 0.05 & $-0.43^{*}$ & $0.21^{*}$ \\
\hline & * Statistically significant at level of 0.05 (two-tailed).
\end{tabular}

The Pearson correlation analysis could provide only the final coefficients, and therefore it was difficult to explore the relationships in detail. As a result, for all the grids (577 in total), 16 regression models were developed to reveal the correlations between LST and the indicators. As mentioned previously, ISA had a warming effect on each season, but the relationship between the area proportion of ISA and LST could not be explored. In spring (Figure 7(a1)), when the area proportion of ISA was between 20 and $40 \%$, both low and high LST values were observed, indicating that LST was affected not only by ISA but also by other factors. The high LST values in these grids with ISA ranging from $20-40 \%$ may have been caused by other warming factors. Some grids with high area proportions of soil also had very high LST, however, others did not. One possible reason was that although both had soil areas, the varying properties of soil resulted in these differences. In summer, this phenomenon disappeared. There were no grids with small ISA area that had high LST values. Therefore, the ISA may be the only warming factor in summer. 

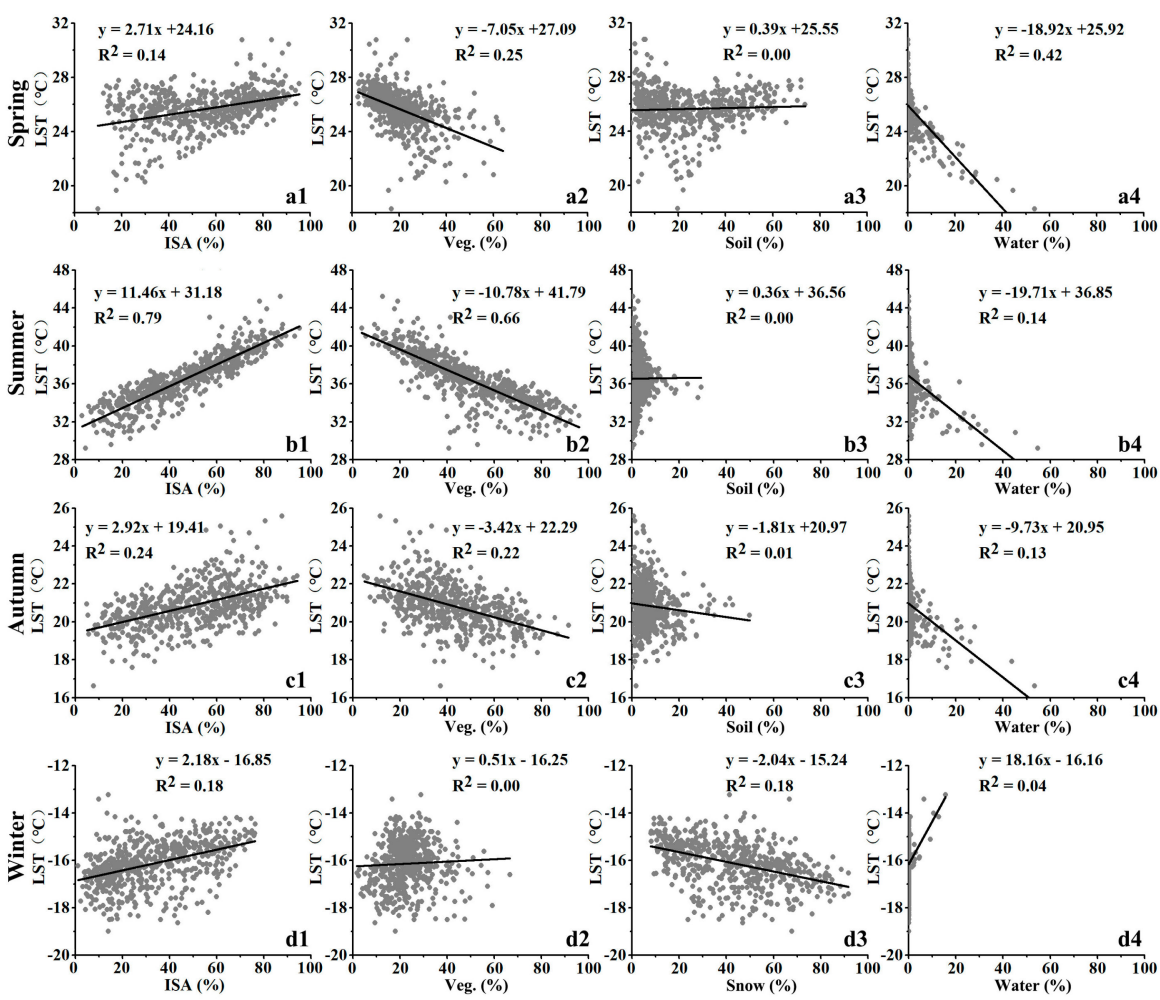

Figure 7. Regression results between LST and driving factors for different seasons ( $n=577)$. (for 'a1-d4': 'a- $d$ ' represent different seasons, a for Spring, b for Summer, c for Autumn and d for winter; '1-4' represent factors, 1 for ISA, 2 for Veg., 3 for soil (snow) and 4 for water).

From a comparison of Figure 7(a2,b2), it could be seen that, for most of the grids, the area proportion of vegetation was less than $40 \%$, and its cooling effect was weaker in spring. In summer, a $10 \%$ increase in the vegetation area in a grid could decrease the LST by $1{ }^{\circ} \mathrm{C}$, which was the strongest effect observed among all the seasons. In winter, there was little relationship between vegetation and LST.

For the effects of soil on the LST, it was difficult to find effective connections based on only the regression model. For most of the grids, their area proportions of soil were less than $10 \%$ (Figure 6(b3)). In winter (Figure 7(d3)), the snow exhibited a cooling effect.

For water, its cooling effect was similar in spring (Figure 7(d1)) and summer (Figure 7(d2)), and was stronger than that of vegetation. In autumn (Figure 7(d3)), the cooling effect of water became slightly weaker because the climate began to cool, and the difference between water and other land-cover types became smaller. In winter (Figure 7(d4)), if one grid had water inside, then its LST would be much higher. A $10 \%$ increase in the water area in a grid could increase the LST by about $1.8^{\circ} \mathrm{C}$.

\section{Discussion}

\subsection{Combined Effects of Driving Factors on LST}

The effect of driving factors on LST has been assessed in previous studies [2,56,57]. However, most of these studies investigated the effect of only a single indicator (such as NDVI, NDBI) on LST, similar to the results shown in Figure 7 in Section 3.4. The combined effects of driving factors on LST, on the other hand, still need to be explored. In this study, we generated 577 grids that were composed of ISA, vegetation, soil, snow, and water bodies, and calculated the corresponding average LST. The LST was sorted from highest to lowest, and the area proportion of each driving factor for each grid was computed at the same time, as shown in Figure 8. 

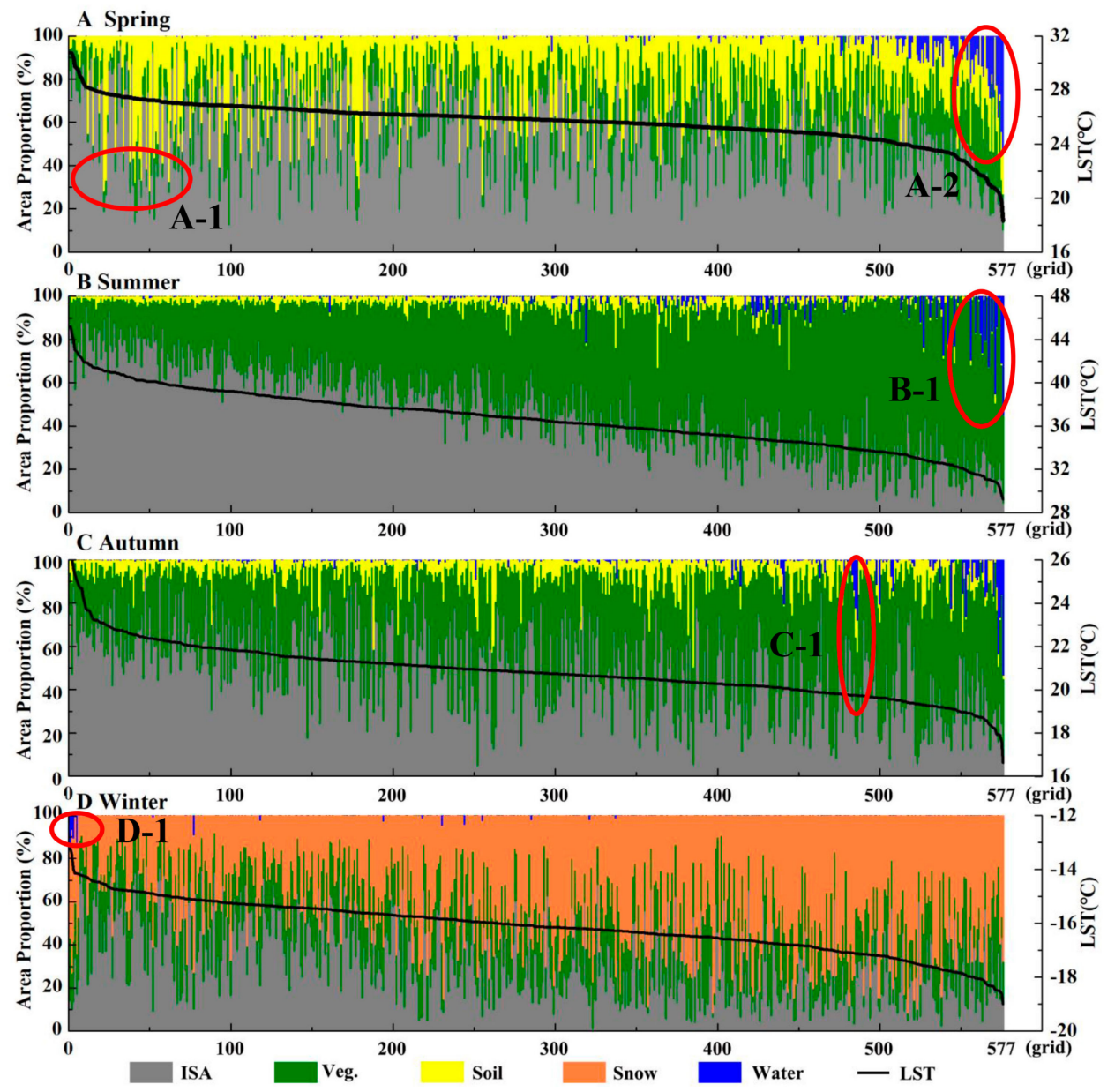

Figure 8. Combined effects of driving factors on LST for different seasons. ('A-D' represent different seasons, A for Spring, B for Summer, C for Autumn and D for winter).

Different driving factors represent different land-cover types that have different thermodynamic properties [58,59]. As a result, a change in grid components will significantly influence the LST. In Figure 8, several phenomena, which have been marked with red circles, attracted our interest and helped us to understand the combined effects of these driving factors. In spring (Figure 8A), red circle A-1 showed that although the area proportion of ISA was not very high, the LST was relatively high. Meanwhile, these grids had high area proportions of soil, indicating that the soil, as a warming factor, may increase the LST. However, for all the grids (577), the relationship between LST and soil was not significant. Thus, the soils in the red circle A-1 may have special properties that need to be investigated.

In red circle A-2, the grids were almost averagely split into four indicators, and water was the dominant driving factor that could sharply decline the LST. In summer (Figure 8B), as expected, with the increase in vegetation and decrease in ISA, the LST declined gradually, which was consistent with previous studies [56,60]; there was a trade-off between these factors.

Similarly, red circle B-1 demonstrated that water bodies could provide a strong cooling effect. The LST in summer was affected by the combined effects of ISA and vegetation, and ISA was the dominant warming factor. In autumn (Figure 8), the effects of ISA and vegetation on LST were weaker compared to those in summer.

Red circle C-1 showed that although the grid had about 25\% water area, its LST was not as low, which was different from what is observed for circle A-2. One possible reason was that the soil factor inside the grid provided a warming effect. For winter (Figure 8D), high LST was always related to grids with water bodies. The mean LST for winter was lower than $-10{ }^{\circ} \mathrm{C}$, and the reason for the presence of liquid water may be anthropogenic heat or geological conditions. The effect of vegetation 
on LST was not significant for winter [61], and the influence of soil on LST was the same as for summer. Snow was the only cooling factor in winter; ISA and water each had a warming effect.

According to an observation of the change curve for LST among the four seasons, the LST decreased sharply at the beginning, and then declined gradually. Finally, the LST had a rapid falling rate. The very high LST were related to large continuous distribution of industrial land with little vegetation cover and dense human activity. In these areas, ISA was the dominant impact factor. Similarly, the very low LST for spring, summer, and autumn were primarily caused by water bodies. In other cases, the LST was influenced by the combined effects of different factors.

\subsection{Seasonal Effects of Driving Factors on LST}

The $30 \mathrm{~m}$ spatial resolution of the Landsat 8 images limited the detailed study of the seasonal variations among the driving factors. As discussed in Section 4.1, it was unclear if special properties of soil could increase LST for some grids in spring. Additionally, the reasons for low-LST areas in winter that were not observed in other seasons were also not clear. Google Earth images provided detailed spatial information that helped us explore potential explanations, and Landsat 8 false-color images enhanced our ability to distinguish different driving factors; for example, vegetation always had a red color in these images. However, the following issue should be considered: there is no meaning in making a comparison if the acquisition time of Google Earth Images and OLI images are not consistent or similar, because of the LULC type and driving factor changes. As shown in Table 1, this study has a good consistency between them.

Sample 1 (Figures 2 and 9) was selected because, in spring, its LST was very high (Figure 9(s1-a1)), whereas its soil was of a large area (Figure 9(s1-a2)). Google Earth images (s1-a3) show that the true color of the soil in the northwest part was black. The local farmers interviewed informed us that they set fire to maize straw around March and April, to kill pests and to create ashes that could serve as fertilizer. Therefore, the high LST in the west part in spring (Figure 4, March and April) for these soils might be related to the burned area. The spatial patterns of LST were also considerably affected by human activities. In summer, the soil became vegetation (s1-b2 and s1-b3), and the LST was much lower compared to that of airfield runways in the southeast part. In winter, the flat ground was covered with snow, except for the airport, which had high LST. The phenological characteristics of vegetation in different seasons would affect the LST significantly.
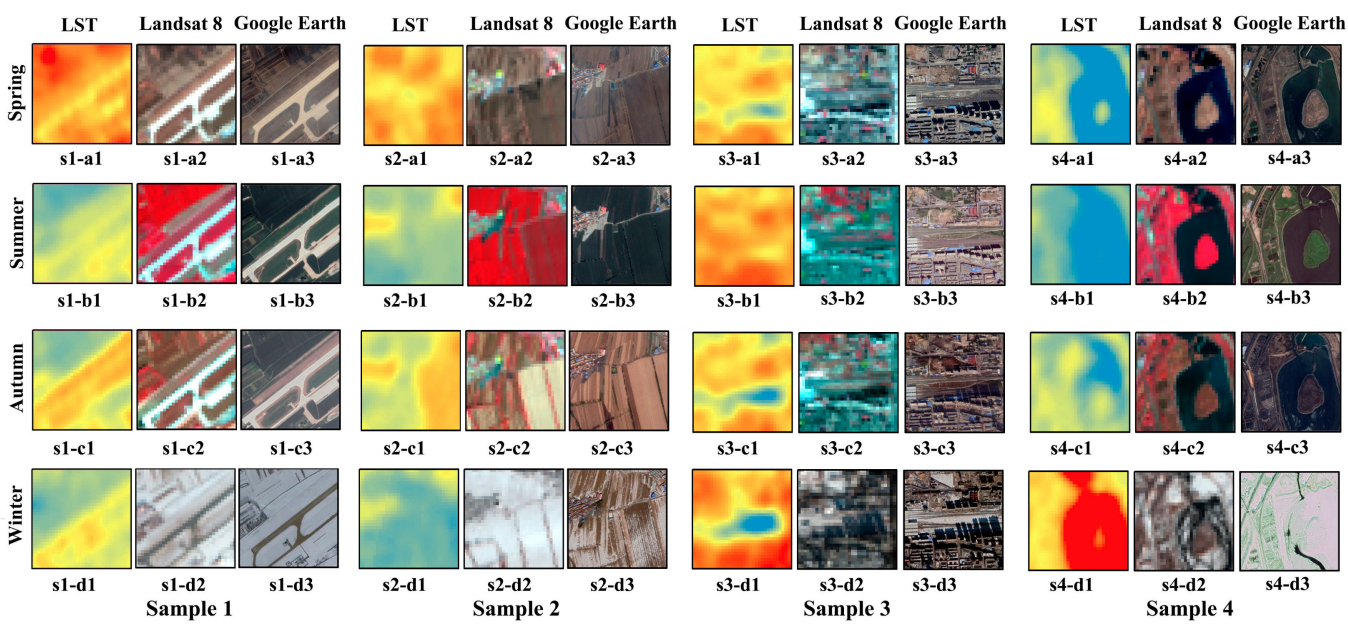

Figure 9. LST, Landsat 8 (false-color), and Google Earth images (true-color) of selected four samples. (for 's1-a1 to s4-d3': 's1-s4' represent sample 1-4; 'a-d' represent different seasons, a for Spring, b for Summer, c for Autumn and d for Winter).

Sample 2 was chosen to explain why LST, due to the same driving factor (soil) for the same season (autumn, s2-c1, left part vs. right part), had huge differences. According to the Landsat 8 false-color 
images (s2-c2), there were obvious differences in the soil because the degrees of roughness of the soils were quite different. The right part was fine and smooth, and was not divided into several small plots. The reason behind this set-up may have been different ways of farming or different choices in crops. The detailed properties of the same driving factors would also influence the LST.

Sample 3 was used to illuminate why low-LST regions were present in winter and not observed in summer. As shown in s3-d1, there was a very-low-LST area (blue color) in the center of the grid. Both the Landsat $(\mathrm{s} 3-\mathrm{d} 2)$ and Google Earth $(\mathrm{s} 3-\mathrm{d} 3)$ images show that a large area of shade was produced by high buildings because of the very low solar altitude in winter, whereas in summer, the shade of buildings accounted for only a small area. It was discussed by some studies whether grey buildings always elevate urban LST [62,63]. However, it was found that the large area of shade generated by high buildings could lower LST in winter. As a result, compared to average LST of the 4-5 ring roads, the very low LST in the urban area, produced by large area of shade, might explain why there is a negative SUHI in winter without snow cover. The changes in solar altitude in different seasons could result in the seasonal variations of LST. It made us to think that although the area proportion of ISA was a good indicator for studying the effect of man-made buildings on LST, a more detailed composition of ISA would help us gain a more comprehensive understanding of its mechanism on LST.

Sample 4 was a part of Yitong River. The cooling effect of the water body on LST was significant for all the seasons, except for winter, when water exhibited a warming effect. It is well known that water has a higher specific heat capacity than those of other land-cover types. In hot seasons, although the water occupied only a small area, its ability to mitigate SUHI was much stronger than those of other factors, due to its evaporative cooling [64]. Meanwhile, the warming effect in winter might help to reduce energy consumption for heating in a snow-climate city such as Changchun.

\subsection{Implications for Urban Planning}

Our results underscore that the spatial patterns of LST exhibited considerable monthly and seasonal variations. These variations were caused by a combined effect of land surface biophysical indicators and human activities. However, because of seasonal variations in the received solar radiation and solar altitude, the status of driving factors and human activities changed considerably. As a result, for urban planners and decision makers, the climate and phenological characteristics of a city should first be considered [65]. The statuses of different driving factors affecting LST in snow-climate cities, such as Changchun, had huge seasonal changes. The dominant driving factors were different across different seasons. For example, the effect of vegetation on LST in summer (high vegetation coverage) and winter (without leaves) varied widely. Therefore, different measures should be made to regulate LST. In spring, human activities on soil could elevate LST, and therefore policy could be made to guide the agricultural activities of farmers. In summer, the cooling effect of water was stronger than that of vegetation, and thus adding a water region seemed to be a more effective way of mitigating the negative effects of UHI. In winter, shade would exacerbate cold waves, and thus building heights should also be considered as one of the driving factors that could regulate LST. As the results have shown, snow can decline LST in winter, and thus clearing snow quickly would help to regulate the climate. In a word, from the perspective of regulating the thermal environment in future urban planning, the following indicators should be considered based on our results: the background climate features (different climate zone), the seasonal effects of different factors on LST, the dominant driving factor in different seasons, and the human activities and others related to SUHI.

\subsection{Limitations}

The results from this study are likely to be subject to several limitations. First, due to data limitation, we only used a single day to represent one month, and this may yield incomplete or even opposite results, compared to previous studies. The $30 \mathrm{~m}$ spatial resolution of Landsat 8 made it very difficult to depict information on the driving factors in better detail. In this study, only the seasonal area proportions of the factors were used in exploring the effects of these factors on LST. 
However, the compositions of neither ISA nor vegetation were provided. For example, it was unclear whether the ISA was made up of parking lots or low buildings. Second, in addition to land surface biophysical indicators, the effect of human activities on LST could not be ignored. However, in this study, we used only qualitative analysis to explore the influence of human beings on LST. In future studies, socio-economic indicators, such as GDP, population, and energy consumption intensity, could be employed in quantifying the effects of these indicators on LST. Third, a different choice of samples may also yield very different results, especially for winter, as the snow cover in this area has an important influence on LST. In our study, we only analyzed the samples with snow cover in winter. One may get very different results if the analysis is based on winter without snow cover. In the future, seasonal variations in nocturnal LST can be investigated using multi-source data, to have a more comprehensive understanding of the mechanism of SUHI.

\section{Conclusions}

Twelve Landsat 8 images were used to retrieve LST for different months, to characterize the seasonal patterns of the urban thermal environment of the snow-climate city Changchun. The seasonal effect of the driving factors of LST were also investigated, because the causes and patterns of such variations were unclear. Several conclusions were made based on our results.

(1) The spatial patterns of LST in Changchun city underwent intense seasonal changes. High LST was concentrated in the urban center in the summer and winter seasons, wherein the SUHI intensities were 4.89 and $1.94{ }^{\circ} \mathrm{C}$, respectively. However, an "inverse" SUHI phenomenon was observed in February, March, and November, when the LST of the soil surrounding the city was relatively high. It is should be noted that these conclusions are based on LST data for a snow-climate city (Changchun).

(2) The status of the driving factors also had seasonal variations due to changes in the incoming solar radiation, which had different impacts on LST in different seasons. The phenological characteristics of vegetation caused changes in area proportion for the different seasons, which affected LST in different ways. The area proportion of ISA in summer was slightly lower than those in spring and autumn because of high vegetation coverage. Almost half of the area was covered with snow, which caused low LST in winter.

(3) The effects of driving factors on LST had considerable variations. The dominant factors were quite different for different seasons. Although LST possessed a positive relationship with ISA for all the seasons, the impact of ISA on LST was most significant for summer. For spring, high LST was related not only to high ISA but also to burned soil. For summer, the changes in LST were sensitive to trade-offs between ISA and vegetation, and soil had little influence. For autumn, ISA and vegetation were still the dominant driving factors, but their impacts were a little weaker than those in summer. For winter, the effect of vegetation was not obvious, and snow became the most important driving factor, which could have led to the lowest average LST $\left(-19.12{ }^{\circ} \mathrm{C}\right)$ in December. The large areas of shade caused by high buildings could have generated low LST regions that exacerbated cold waves. Meanwhile, despite its small area proportion, water had the strongest cooling effect from spring to autumn and had a warming effect in winter.

(4) The effects of human activities on LST could not be ignored. For example, agricultural burning activities in March and November, harvesting dates in autumn, different selections of crops, and energy costs for air conditioning in summer and heating in winter all affect the spatial patterns of LST. These important factors should also be considered in future urban planning.

Author Contributions: Conceptualization, C.Y.; methodology, F.Y.; software, X.L.; validation, X.D.; formal analysis, L.L.; investigation, C.Y.; resources, X.D.; data curation, S.Z.; writing-Original draft preparation, C.Y.; writing-Review and editing, C.Y.; visualization, Y.Z.; supervision, S.Z.; project administration, C.Y. All authors have read and agreed to the published version of the manuscript.

Funding: This research was funded project ZR2019BD036 funded by Shandong Provincial Natural Science Foundation, China.

Acknowledgments: Thank the Elsevier Language Editing Services for help with English editing. 
Conflicts of Interest: The authors declare no conflict of interest.

\section{References}

1. Kalnay, E.; Cai, M. Impact of urbanization and land-use change on climate. Nature 2003, 423, 528. [CrossRef] [PubMed]

2. Grigoraș, G.; Urițescu, B. Land Use/Land Cover changes dynamics and their effects on Surface Urban Heat Island in Bucharest, Romania. Int. J. Appl. Earth Obs. Geoinf. 2019, 80, 115-126. [CrossRef]

3. Rizwan, A.M.; Dennis, L.Y.C.; Liu, C. A review on the generation, determination and mitigation of Urban Heat Island. J. Environ. Sci. 2008, 20, 120-128. [CrossRef]

4. Deilami, K.; Kamruzzaman, M.; Liu, Y. Urban heat island effect: A systematic review of spatio-temporal factors, data, methods, and mitigation measures. Int. J. Appl. Earth Obs. Geoinf. 2018, 67, 30-42. [CrossRef]

5. Zhou, D.; Xiao, J.; Bonafoni, S.; Berger, C.; Deilami, K.; Zhou, Y.; Frolking, S.; Yao, R.; Qiao, Z.; Sobrino, J. Satellite Remote Sensing of Surface Urban Heat Islands: Progress, Challenges, and Perspectives. Remote Sens. 2018, 11, 48. [CrossRef]

6. Arnfield, A.J. Two decades of urban climate research: A review of turbulence, exchanges of energy and water, and the urban heat island. Int. J. Climatol. 2003, 23, 1-26. [CrossRef]

7. McMichael, A.J.; Woodruff, R.E.; Hales, S. Climate change and human health: Present and future risks. Lancet 2006, 367, 859-869. [CrossRef]

8. Mahmoud, S.H.; Gan, T.Y. Long-term impact of rapid urbanization on urban climate and human thermal comfort in hot-arid environment. Build. Environ. 2018, 142, 83-100. [CrossRef]

9. Weng, Q. Thermal infrared remote sensing for urban climate and environmental studies: Methods, applications, and trends. ISPRS J. Photogramm. Remote Sens. 2009, 64, 335-344. [CrossRef]

10. Voogt, J.A.; Oke, T.R. Thermal remote sensing of urban climates. Remote Sens. Environ. 2003, 86, 370-384. [CrossRef]

11. Yuan, F.; Bauer, M.E. Comparison of impervious surface area and normalized difference vegetation index as indicators of surface urban heat island effects in Landsat imagery. Remote Sens. Environ. 2007, 106, 375-386. [CrossRef]

12. Kourtidis, K.; Georgoulias, A.; Rapsomanikis, S.; Amiridis, V.; Keramitsoglou, I.; Hooyberghs, H.; Maiheu, B.; Melas, D. A study of the hourly variability of the urban heat island effect in the Greater Athens Area during summer. Sci. Total Environ. 2015, 517, 162-177. [CrossRef] [PubMed]

13. Yang, C.; Wang, R.; Zhang, S.; Ji, C.; Fu, X. Characterizing the Hourly Variation of Urban Heat Islands in a Snowy Climate City during Summer. Int. J. Environ. Res. Public Health 2019, 16, 2467. [CrossRef] [PubMed]

14. Dodson, R.; Marks, D. Daily air temperature interpolated at high spatial resolution over a large mountainous region. Clim. Res. 1997, 8, 1-20. [CrossRef]

15. Yang, C.; Yan, F.; Zhang, S. Comparison of land surface and air temperatures for quantifying summer and winter urban heat island in a snow climate city. J. Environ. Manag. 2020, 265, 110563. [CrossRef]

16. Hu, Y.; Hou, M.; Jia, G.; Zhao, C.; Zhen, X.; Xu, Y. Comparison of surface and canopy urban heat islands within megacities of eastern China. ISPRS J. Photogramm. Remote Sens. 2019, 156, 160-168. [CrossRef]

17. Sheng, L.; Tang, X.; You, H.; Gu, Q.; Hu, H. Comparison of the urban heat island intensity quantified by using air temperature and Landsat land surface temperature in Hangzhou, China. Ecol. Indic. 2017, 72, 738-746. [CrossRef]

18. Yao, R.; Wang, L.; Huang, X.; Niu, Y.; Chen, Y.; Niu, Z. The influence of different data and method on estimating the surface urban heat island intensity. Ecol. Indic. 2018, 89, 45-55. [CrossRef]

19. Liu, F.; Zhang, X.; Murayama, Y.; Morimoto, T. Impacts of Land Cover/Use on the Urban Thermal Environment: A Comparative Study of 10 Megacities in China. Remote Sens. 2020, 12, 307. [CrossRef]

20. Guo, A.; Yang, J.; Xiao, X.; Xia, J.; Jin, C.; Li, X. Influences of urban spatial form on urban heat island effects at the community level in China. Sustain. Cities Soc. 2020, 53, 101972. [CrossRef]

21. Jamei, Y.; Rajagopalan, P.; Sun, Q. Spatial structure of surface urban heat island and its relationship with vegetation and built-up areas in Melbourne, Australia. Sci. Total Environ. 2019, 659, 1335-1351. [CrossRef]

22. Peres, L.d.F.; Lucena, A.J.d.; Rotunno-Filho, O.C.; França, J.R.d.A. The urban heat island in Rio de Janeiro, Brazil, in the last 30 years using remote sensing data. Int. J. Appl. Earth Obs. Geoinf. 2018, 64, 104-116. [CrossRef] 
23. Kalnay, E.; Cai, M.; Li, H.; Tobin, J. Estimation of the impact of land-surface forcings on temperature trends in eastern United States. J. Geophys. Res. Atmos. 2006, 111. [CrossRef]

24. Weng, Q.; Fu, P.; Gao, F. Generating daily land surface temperature at Landsat resolution by fusing Landsat and MODIS data. Remote Sens. Environ. 2014, 145, 55-67. [CrossRef]

25. Li, X.; Zhou, W. Spatial patterns and driving factors of surface urban heat island intensity: A comparative study for two agriculture-dominated regions in China and the USA. Sustain. Cities Soc. 2019, 48, 101518. [CrossRef]

26. Alexander, C. Normalised difference spectral indices and urban land cover as indicators of land surface temperature (LST). Int. J. Appl. Earth Obs. Geoinf. 2020, 86, 102013. [CrossRef]

27. Peng, J.; Jia, J.; Liu, Y.; Li, H.; Wu, J. Seasonal contrast of the dominant factors for spatial distribution of land surface temperature in urban areas. Remote Sens. Environ. 2018, 215, 255-267. [CrossRef]

28. Berger, C.; Rosentreter, J.; Voltersen, M.; Baumgart, C.; Schmullius, C.; Hese, S. Spatio-temporal analysis of the relationship between 2D/3D urban site characteristics and land surface temperature. Remote Sens. Environ. 2017, 193, 225-243. [CrossRef]

29. Yang, Q.; Huang, X.; Li, J. Assessing the relationship between surface urban heat islands and landscape patterns across climatic zones in China. Sci. Rep. 2017, 7, 9337. [CrossRef]

30. Schwarz, N.; Lautenbach, S.; Seppelt, R. Exploring indicators for quantifying surface urban heat islands of European cities with MODIS land surface temperatures. Remote Sens. Environ. 2011, 115, 3175-3186. [CrossRef]

31. Yao, R.; Wang, L.; Huang, X.; Niu, Z.; Liu, F.; Wang, Q. Temporal trends of surface urban heat islands and associated determinants in major Chinese cities. Sci. Total Environ. 2017, 609, 742-754. [CrossRef] [PubMed]

32. Chen, L.; Dirmeyer, P.A. Adapting observationally based metrics of biogeophysical feedbacks from land cover/land use change to climate modeling. Environ. Res. Lett. 2016, 11, 034002. [CrossRef]

33. Gallo, K.P.; Tarpley, J.D. The comparison of vegetation index and surface temperature composites for urban heat-island analysis. Int. J. Remote Sens. 1996, 17, 3071-3076. [CrossRef]

34. Deng, C.; Wu, C. Examining the impacts of urban biophysical compositions on surface urban heat island: A spectral unmixing and thermal mixing approach. Remote Sens. Environ. 2013, 131, 262-274. [CrossRef]

35. Ridd, M.K. Exploring a V-I-S (vegetation-impervious surface-soil) model for urban ecosystem analysis through remote sensing: Comparative anatomy for cities. Int. J. Remote Sens. 1995, 16, 2165-2185. [CrossRef]

36. Li, J.; Song, C.; Cao, L.; Zhu, F.; Meng, X.; Wu, J. Impacts of landscape structure on surface urban heat islands: A case study of Shanghai, China. Remote Sens. Environ. 2011, 115, 3249-3263. [CrossRef]

37. Zhong, Q.; Ma, J.; Zhao, B.; Wang, X.; Zong, J.; Xiao, X. Assessing spatial-temporal dynamics of urban expansion, vegetation greenness and photosynthesis in megacity Shanghai, China during 2000-2016. Remote Sens. Environ. 2019, 233, 111374. [CrossRef]

38. Weng, Q.; Lu, D.; Schubring, J. Estimation of land surface temperature-vegetation abundance relationship for urban heat island studies. Remote Sens. Environ. 2004, 89, 467-483. [CrossRef]

39. Huang, G.; Cadenasso, M.L. People, landscape, and urban heat island: Dynamics among neighborhood social conditions, land cover and surface temperatures. Landsc. Ecol. 2016, 31, 2507-2515. [CrossRef]

40. Li, L.; Yu, T.; Zhao, L.; Zhan, Y.; Zheng, F.; Zhang, Y.; Mumtaz, F.; Wang, C. Characteristics and trend analysis of the relationship between land surface temperature and nighttime light intensity levels over China. Infrared Phys. Technol. 2019, 97, 381-390. [CrossRef]

41. Huang, X.; Wang, Y. Investigating the effects of 3D urban morphology on the surface urban heat island effect in urban functional zones by using high-resolution remote sensing data: A case study of Wuhan, Central China. ISPRS J. Photogramm. Remote Sens. 2019, 152, 119-131. [CrossRef]

42. Yin, C.; Yuan, M.; Lu, Y.; Huang, Y.; Liu, Y. Effects of urban form on the urban heat island effect based on spatial regression model. Sci. Total Environ. 2018, 634, 696-704. [CrossRef] [PubMed]

43. Cheung, P.K.; Jim, C.Y. Effects of urban and landscape elements on air temperature in a high-density subtropical city. Build. Environ. 2019, 164, 106362. [CrossRef]

44. Acero, J.A.; González-Asensio, B. Influence of vegetation on the morning land surface temperature in a tropical humid urban area. Urban Clim. 2018, 26, 231-243. [CrossRef]

45. Fang, Z.; Feng, X.; Liu, J.; Lin, Z.; Mak, C.M.; Niu, J.; Tse, K.-T.; Xu, X. Investigation into the differences among several outdoor thermal comfort indices against field survey in subtropics. Sustain. Cities Soc. 2019, 44, 676-690. [CrossRef] 
46. Yang, C.; He, X.; Yu, L.; Yang, J.; Yan, F.; Bu, K.; Chang, L.; Zhang, S. The Cooling Effect of Urban Parks and Its Monthly Variations in a Snow Climate City. Remote Sens. 2017, 9, 1066. [CrossRef]

47. Yang, C.; He, X.; Yan, F.; Yu, L.; Bu, K.; Yang, J.; Chang, L.; Zhang, S. Mapping the influence of land use/land cover changes on the urban heat island effect-A case study of Changchun, China. Sustainability 2017, 9, 312. [CrossRef]

48. Kottek, M.; Grieser, J.; Beck, C.; Rudolf, B.; Rubel, F. World map of the Köppen-Geiger climate classification updated. Meteorol. Z. 2006, 15, 259-263. [CrossRef]

49. USGS. Landsat 8 Hand Book. 2016. Available online: https://www.usgs.gov/media/files/landsat-8-datausers-handbook (accessed on 14 September 2020).

50. Sobrino, J.A.; Jiménez-Muñoz, J.C.; Paolini, L. Land surface temperature retrieval from LANDSAT TM 5. Remote Sens. Environ. 2004, 90, 434-440. [CrossRef]

51. $\mathrm{Xu}, \mathrm{H}$. Study on information extraction of water body with the modified normalized difference water index (MNDWI). J. Remote Sens. 2005, 9, 589-595.

52. Wu, C.; Murray, A.T. Estimating impervious surface distribution by spectral mixture analysis. Remote Sens. Environ. 2003, 84, 493-505. [CrossRef]

53. Wu, C. Normalized spectral mixture analysis for monitoring urban composition using ETM+ imagery. Remote Sens. Environ. 2004, 93, 480-492. [CrossRef]

54. Liu, W.; Ji, C.; Zhong, J.; Jiang, X.; Zheng, Z. Temporal characteristics of the Beijing urban heat island. Theor. Appl. Climatol. 2007, 87, 213-221. [CrossRef]

55. Yang, P.; Ren, G.; Liu, W. Spatial and Temporal Characteristics of Beijing Urban Heat Island Intensity. J. Appl. Meteorol. Climatol. 2013, 52, 1803-1816. [CrossRef]

56. Masoudi, M.; Tan, P.Y. Multi-year comparison of the effects of spatial pattern of urban green spaces on urban land surface temperature. Landsc. Urban Plan. 2019, 184, 44-58. [CrossRef]

57. Wang, Y.-C.; Hu, B.K.H.; Myint, S.W.; Feng, C.-C.; Chow, W.T.L.; Passy, P.F. Patterns of land change and their potential impacts on land surface temperature change in Yangon, Myanmar. Sci. Total Environ. 2018, 643, 738-750. [CrossRef]

58. Guo, G.; Wu, Z.; Xiao, R.; Chen, Y.; Liu, X.; Zhang, X. Impacts of urban biophysical composition on land surface temperature in urban heat island clusters. Landsc. Urban Plan. 2015, 135, 1-10. [CrossRef]

59. He, B.; Zhao, Z.; Shen, L.; Wang, H.; Li, L. An approach to examining performances of cool/hot sources in mitigating/enhancing land surface temperature under different temperature backgrounds based on landsat 8 image. Sustain. Cities Soc. 2019, 44, 416-427. [CrossRef]

60. Li, X.; Zhou, W. Optimizing urban greenspace spatial pattern to mitigate urban heat island effects: Extending understanding from local to the city scale. Urban For. Urban Green. 2019, 41, 255-263. [CrossRef]

61. Yang, C.; He, X.; Wang, R.; Yan, F.; Yu, L.; Bu, K.; Yang, J.; Chang, L.; Zhang, S. The Effect of Urban Green Spaces on the Urban Thermal Environment and Its Seasonal Variations. Forests 2017, 8, 153. [CrossRef]

62. Qi, J.-D.; He, B.-J.; Wang, M.; Zhu, J.; Fu, W.-C. Do grey infrastructures always elevate urban temperature? No, utilizing grey infrastructures to mitigate urban heat island effects. Sustain. Cities Soc. 2019, 46, 101392. [CrossRef]

63. Zheng, Z.; Zhou, W.; Yan, J.; Qian, Y.; Wang, J.; Li, W. The higher, the cooler? Effects of building height on land surface temperatures in residential areas of Beijing. Phys. Chem. Earth Parts A/B/C 2019, 110, 149-156. [CrossRef]

64. Wu, C.; Li, J.; Wang, C.; Song, C.; Chen, Y.; Finka, M.; la Rosa, D. Understanding the relationship between urban blue infrastructure and land surface temperature. Sci. Total Environ. 2019, 694, 133742. [CrossRef]

65. He, B. Potentials of meteorological characteristics and synoptic conditions to mitigate urban heat island effects. Urban Clim. 2018, 24, 26-33. [CrossRef]

(C) 2020 by the authors. Licensee MDPI, Basel, Switzerland. This article is an open access article distributed under the terms and conditions of the Creative Commons Attribution (CC BY) license (http://creativecommons.org/licenses/by/4.0/). 